\title{
Consumer Views:
} Importance of Fuel Economy

\section{Mark Singer}

April 2017

NREL/PR-5400-68200 


\section{Consumer views on the importance of fuel economy}

\section{Overview}

This presentation includes data captured by the National Renewable Energy Laboratory (NREL) to support the U.S. Department of Energy's Vehicle Technologies Office (VTO) research efforts. The data capture consumer views on the importance of fuel economy amongst other vehicle attributes.

NREL provides consumer preference data to support the prioritization of development efforts by identifying barriers to and opportunities for new technologies.

\section{Methodology}

The data presented are the results of interviews conducted by the Opinion Research Corporation (ORC) for NREL. The interviews were conducted via telephone with randomly selected telephone numbers. The study used a dual-frame sampling design in which the sample was drawn from independent landline and cell phone sample frames and is based on responses from individuals across the country who were at least 18 years old. Response samples were weight-adjusted to better ensure that the sample reflects the general U.S. population. The studies relied on ORC's weighting mechanism, which pulls from data reported in the National Health Interview Survey and the U.S. Census Bureau's Current Population Survey. A June 2015 study included 1,006 respondents and a June 2016 study included 1,012 respondents. Both studies had a margin of error of $\pm 3 \%$ at the $95 \%$ confidence level. Smaller subgroups of the respondents will have larger error margins. 


\section{Importance of fuel economy}

The June 2015 and June 2016 studies asked respondents which vehicle attribute was most important amongst fuel economy, dependability, safety, quality, and low cost. The question has been asked periodically since 1996. 


\section{Vehicle attribute preferences}

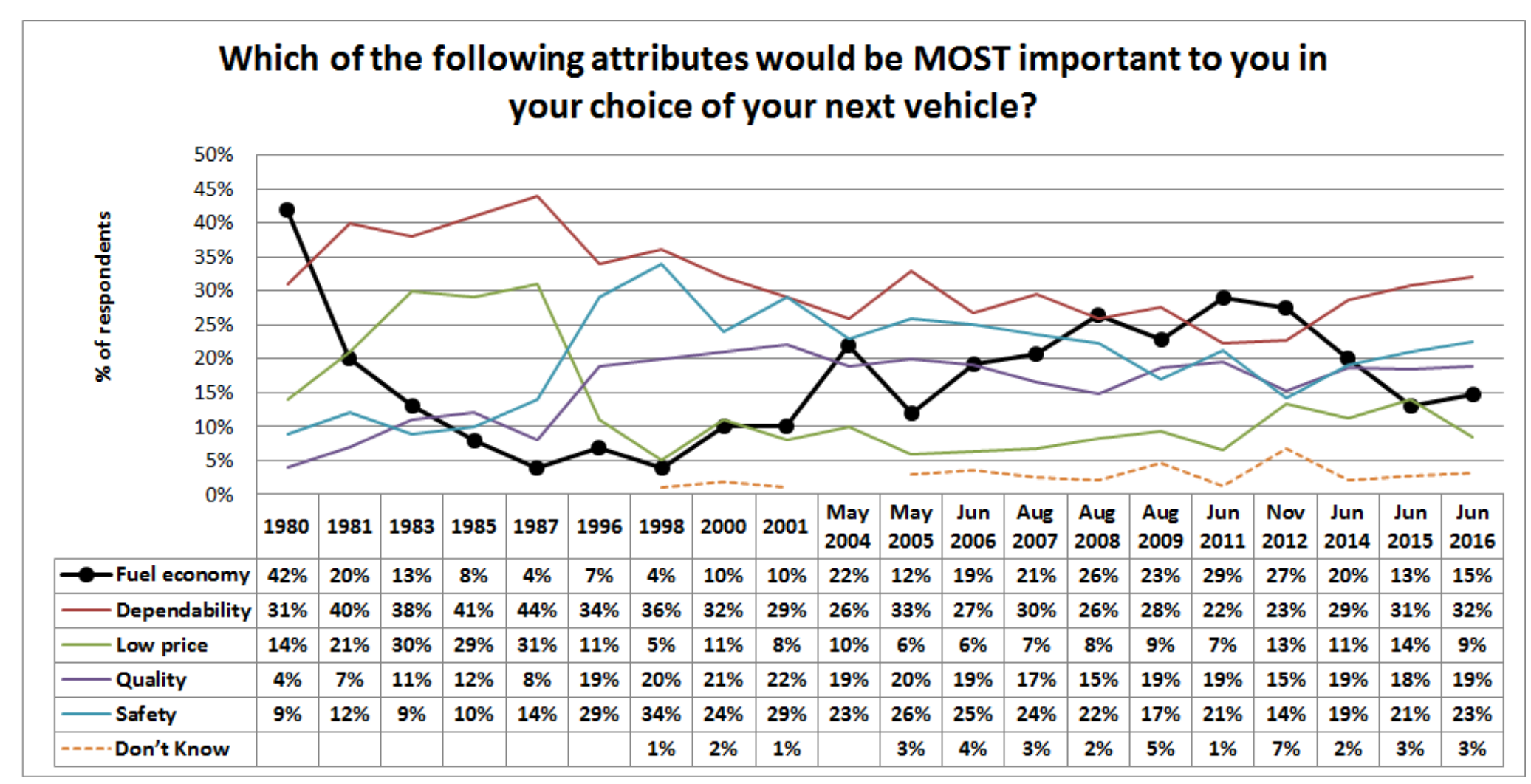

\section{Sources:}

ORC for NREL (June 2015), Study No. 724268, n=1,006.

ORC for NREL (June 2016), Study No. 725268, n=1,012.

June 2014 and before:

Consumer Views on Transportation and Advanced Vehicle Technologies (http://www.nrel.gov/docs/fy15osti/64840.pdf)

The importance of fuel economy in June 2016 rose slightly from the last study in June 2015, but remains low in comparison to the preceding ten years. 


\section{Vehicle attribute preference and gasoline price}

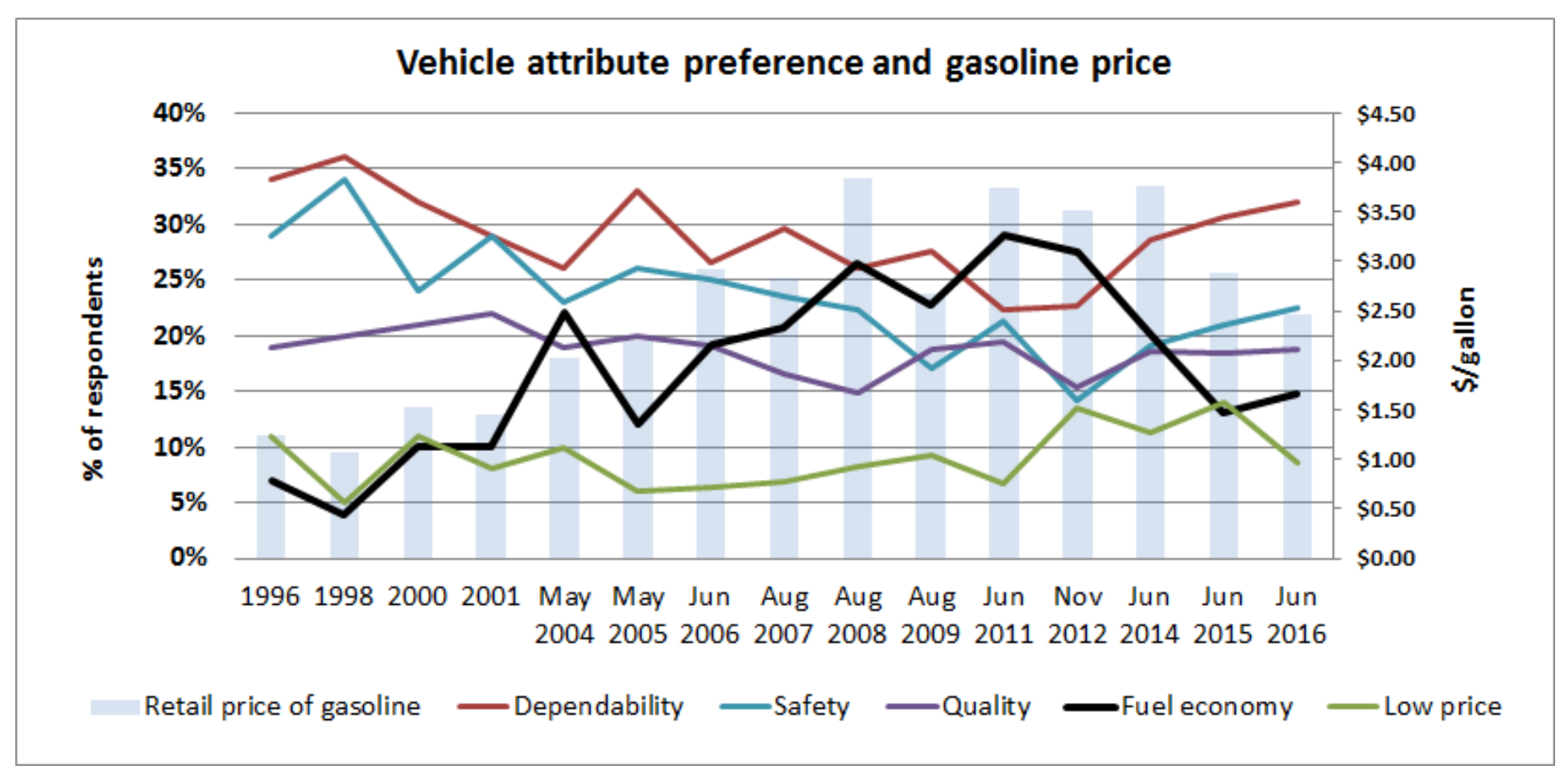

\section{Sources:}

ORC for NREL (June 2015), Study No. 724268, n=1,006.

ORC for NREL (June 2016), Study No. 725268, n=1,012.

June 2014 and before:

Consumer Views on Transportation and Advanced Vehicle Technologies (http://www.nrel.gov/docs/fy15osti/64840.pdf) U.S. All Grades All Formulations Retail Gasoline Prices (http://www.eia.gov/petroleum/gasdiesel/)

The relative importance of fuel economy appears to trend similarly to gasoline price. Fuel economy tends to be more important to respondents when gasoline prices are higher. 


\section{Mark Singer \\ Mark.Singer@NREL.GOV}

